\title{
Personality and Conditioning: A Test of Four Models
}

\author{
Richard Zinbarg and William Revelle \\ Northwestern University
}

\begin{abstract}
Four experiments were conducted to test hypotheses derived from 4 alternative models of individual differences in instrumental conditioning. A standard go-no-go discrimination learning task was used in each of the 4 experiments. The results indicate that individual differences in performance of this discrimination are more consistently and strongly associated with impulsivity and anxiety than with extraversion and neuroticism. In each of the experiments, high anxiety hindered the learning of a go-no-go discrimination more among high impulsive Ss than among low impulsive Ss, and in 2 of the experiments high anxiety actually facilitated learning among low impulsive Ss. These findings are incompatible with Eysenck's and Gray's hypotheses regarding extraversion but are not inconsistent with Newman's. Aspects of these results do support Spence's and Gray's models of anxiety and instrumental conditioning. However, both of these models were contradicted by other trends in the data. A modification of Gray's model of impulsivity and anxiety that emphasizes the role of expectancies was proposed to fit these data.
\end{abstract}

Conditioning has often been assigned a crucial role in theories of personality development (H. J. Eysenck, 1967), abnormal behavior (Dollard \& Miller, 1950; Mowrer, 1969), and socialization (Aronfreed, 1968; H. J. Eysenck, 1977; Trasler, 1978). Studies of individual differences in conditionability may therefore help to identify some of the factors that predispose individuals to psychopathology and antisocial behavior.

Early investigations of the relation between personality and conditioning were conducted by Bird (1927), Forlano and Axelrod (1937), and Thompson and Hunnicutt (1944). ${ }^{1}$ Since the time of these pioneering investigations, interest in the relation between personality and conditioning has waxed and waned. In their review of the literature investigating personality and conditioning, Levey and Martin (1981) noted that interest in the relation between personality and conditioning generated a great deal of research activity throughout the 1950s and 1960s. Much of this interest centered on the theoretical controversy between H. J. Eysenck's $(1957,1965)$ theory of extraversion and the Spences' (K. W. Spence \& Taylor, 1951; J. T. Spence \& Spence,

Preparation of this article was supported in part by National Institute of Mental Health Fellowship MH 09643 to Richard Zinbarg.

This article is based on a thesis submitted by Richard Zinbarg in partial fulfillment of the Master of Arts degree at Northwestern University. Portions of this article are also based on a paper entitled "Personality and Conditionability: An Empirical Test of Three Models" that was presented at the third meeting of the International Society for the Study of Individual Differences, June 1987, Toronto, Canada.

We would like to thank Lauren Alloy, Richard Bootzin, and Winfred Hill for their contribution to the thesis, Joseph Newman and two anonymous reviewers for their valuable comments on earlier drafts of this article, and Nishad Nadkarni for his assistance in conducting these experiments.

Correspondence concerning this article should be addressed to Richard Zinbarg, who is now at the Phobia and Anxiety Disorders Clinic, State University of New York at Albany, 1535 Western Avenue, Albany, New York 12203.
1966) theory of anxiety. One of the outcomes of this controversy and the large body of research it spawned was the clarification of each theory. In other words, the boundary conditions of each theory were established such that the stimulus conditions under which each theory should hold true were identified.

Commenting on the relative neglect of the relation between personality and conditioning over the past two decades, Levey and Martin (1981) stated that "individual differences are frequently reported in conditioning studies, though their systematic study remains an area of neglect" (p. 123). They attributed this neglect to at least three factors. First, interest in the area may have declined, at least in part, as a result of the partial resolution of the controversy between $\mathbf{H}$. J. Eysenck and the Spences. Second, work on conditioning in the past two decades has tended to involve a growing appreciation for the complexity of conditioning phenomena and an emphasis on cognitive variables in conditioning. Third, research in conditioning has been dominated by an empirical approach with less interest in allembracing systems such as that proposed by Hull (1943).

As Levey and Martin (1981) predicted, there seems to have been some revival of interest in personality and conditionability in the past few years. This revival of interest centers around H. J. Eysenck's (1967, 1977; H. J. Eysenck \& Eysenck, 1985) theory of personality and two modifications of this theory (Gray, 1982; Newman, Widom, \& Nathan, 1985), each of which has drawn on learning theory to elucidate and enrich the description and explanation of personality structure. It is obvious that the study of personality and conditioning has direct bearing on the current debate between these three theories. In addition, studies of personality and conditioning may even shed further light on conditioning phenomena in general (Levey \& Martin, 1981).

In this article, we report on four experiments testing predic-

\footnotetext{
${ }^{1}$ Of course, the study of individual differences in conditioning traces back to Pavlov's (1927) studies of "sanguine," "melancholic," "phlegmatic," and "choleric" dogs.
} 
tions derived from four alternative models of personality and conditioning. Three of these models are currently at the center of controversy in this area (i.e., those of Eysenck, Gray, and Newman). We also included the Spences' theory because of its historical significance and impact on the field. The primary purpose of these experiments was to begin to compare the relative efficacy of these theories in accounting for individual differences in conditioning. Before describing the specific experiments, however, it is necessary to outline each of the four theories and clarify the differences among them. ${ }^{2}$

\section{Four Theories of Personality and Conditioning}

\section{The Spences' Theory}

Drive theory, originally developed by Hull (1943), states that the excitatory potential (E) of a response is a multiplicative function of a learning factor, habit strength $(H)$, and drive (D), such that $E=f(H \times D)$. K. W. Spence's (1964) application of drive theory to the study of individual differences in human conditioning rests on the assumption that anxiety is one source of drive. The Spences elaborated on this model and presented a drive theory explanation of the effects of anxiety on tasks that differ in the degree of intratask competition between correct and incorrect responses. On tasks that involve intratask competition, it is possible that the initial habit strength of the correct response is stronger than that of the competing responses. In this case, the higher the level of $D$, the greater is the difference between the $\mathrm{E}$ values of the correct and incorrect competing responses. In instances in which the correct responses are initially strong, performance should be positively related to $D$ and thus to anxiety as well. ${ }^{3}$ On the other hand, if the correct response is initially weak relative to competing response tendencies, then $D$, and thus anxiety, should be negatively related to performance in the early stages of the task. However, as the habit strength of the correct response increases over trials, performance should eventually be positively related to anxiety. Thus, although the performance of a high anxiety group would be expected to be inferior to that of a low anxiety group in the early stages of learning an initially weak response, it should become superior in the later stages of learning the same response.

Drive theory generated a good deal of research, and it appears that the preponderance of the evidence supported the hypotheses concerning the relation between anxiety and performance (e.g., K. W. Spence, 1964; J. T. Spence \& Spence, 1966; but see Weiner, 1966, and Weiner \& Schneider, 1971, for contradictory evidence). However, the Spences (1966) noted that stressful stimulation, in the form of noxious stimuli or ego-involving instructions, is important for producing differences in drive among the anxiety groups.

\section{Eysenck's Theory}

H. J. Eysenck assumed that (a) introverted individuals are more aroused than extraverted individuals and (b) the relation between arousal and conditioning is curvilinear; in other words, increasing arousal facilitates conditioning until an optimal level of arousal is reached. On the basis of these two assumptions, he predicted that introverted individuals condition more readily than extraverted individuals under conditions of low to moderate arousal. When H. J. Eysenck (1967) originally derived this prediction, it was meant to apply only to classical conditioning; however, this prediction has since been extended to apply to instrumental conditioning as well (H. J. Eysenck \& Eysenck, 1985). According to Eysenck (H. J. Eysenck \& Eysenck, 1985), the mechanism that mediates the relation between extraversion and conditioning is that weak unconditioned stimuli should be perceived by introverted individuals as subjectively stronger, and consequently more reinforcing, as their high arousal level acts to amplify incoming sensory stimulation. H. J. Eysenck (1977) also argued that conscience is a set of conditioned reflexes and therefore predicted that extraverted individuals will have weaker consciences than introverted individuals. In fact, Eysenck explains many of the behavioral differences between introverted and extraverted people as resulting directly from this difference in the strength of the conscience and thus indirectly from the difference in their degree of conditionability.

H. J. Eysenck (1965) reviewed the literature examining eyeblink and galvanic skin response conditioning and concluded that, in general, the results supported his prediction. However, he also noted that many experiments failed to find the predicted relation between extraversion and conditionability. In attempting to account for these discrepant findings, Eysenck proposed that three parameters are crucial to obtaining the predicted results. Thus, Eysenck observed that studies using partial reinforcement, weak conditioned stimulus and unconditioned stimulus intensity, or discrimination learning were more likely to yield the result that introverted people condition at higher levels than extraverted people. H. J. Eysenck and Levey (1972) suggested that these three parameter values, in addition to a short conditioned stimulus-unconditioned stimulus interval, favor the development of moderate levels of arousal and therefore lead to optimal levels of arousal among introverted individuals. On the other hand, they suggested that studies not using these parameter values lead to the development of high levels of arousal and therefore to poor conditioning due to overarousal among introverted individuals. In testing this hypothesis, H. J. Eysenck and Levey (1972) found that partial reinforcement was not as important as the other parameter values in producing the predicted relation between extraversion and conditioning.

\section{Gray's Theory}

Gray presented a modification of Eysenck's model of personality to account for several anomalous findings that could not be explained by Eysenck's theory (see Gray, 1981, for an extended critique of Eysenck's model). Gray suggested a $45^{\circ}$ rotation of the dimensions of extraversion $(\mathrm{I} / \mathrm{E})$ and neuroticism $(\mathrm{S} / \mathrm{N})$ to produce the orthogonal dimensions of impulsivity (Imp) and anxiety (Anx). He assumed that increasing levels of Imp reflect

\footnotetext{
${ }^{2}$ Uniess otherwise noted, the references for the Spences, Eysenck, Gray, and Newan are, respectively, J. T. Spence and Spence (1966), H. J, Eysenck (1967, 1977), Gray (1982), and Newman, Widom, and Nathan (1985).

${ }^{3}$ Performance is also predicted to be positively related to anxiety in the case of a task with no intratask competition, such as simple classical conditioning.
} 
increasing levels of sensitivity and behavioral activation to signals of reward or nonpunishment, and that increasing levels of Anx reflect increasing levels of sensitivity and behavioral inhibition to signals of punishment or frustration. Furthermore, I/E was assumed to reflect the relative strength, or balance, of Imp and Anx. That is, individuals who are more sensitive to signals of punishment than to signals of reward are introverted, and individuals who are more sensitive to signals of reward than to signals of punishment are extraverted. On the other hand, S/N was assumed to reflect the joint strength, or the sum, of Imp and Anx.

Although Gray's theory is a modification of H. J. Eysenck's theory, there are critical differences between the two. The most important distinction is with respect to the fundamental causal dimensions each postulates: Eysenck believes that $\mathrm{I} / \mathrm{E}$ and $\mathrm{S} / \mathrm{N}$ are the fundamental dimensions; Gray, that Imp and Anx are of primary importance. Whereas it is impossible to discriminate between these two theories on psychometric grounds, it is at the level of performance that these two theories differ. Because both theories hold that I/E, S/N, Imp, and Anx lie in the same twodimensional space, predictions regarding all four dimensions can be derived from both Eysenck's and Gray's theories. That is, although Eysenck's predictions are couched in the terminology of $\mathrm{I} / \mathrm{E}$ and $\mathrm{S} / \mathrm{N}$, they can be translated in terms of Imp and Anx. ${ }^{4}$

An obvious point at which these two theories make different predictions is performance in an instrumental conditioning task. Both H. J. Eysenck and Gray predicted stronger conditioning in introverted than in extraverted individuals in response to cues for punishment. However, Eysenck's theory continues to predict this introvert superiority in response to cues for reward, in contrast to Gray's theory that predicts extravert superiority in response to cues for reward. To date, the majority of research testing Gray's theory has been investigations of the effects of antianxiety drugs and limbic system lesions in rats (Gray, 1982). Relatively little research has been directed at testing Gray's theory at the human level, although Gray and his colleagues (1981; Gray, Owen, Davis, \& Tsaltas, 1983) have claimed that the available evidence seems supportive.

\section{Newman's Theory}

Newman and his colleagues (Newman, Widom, \& Nathan, 1985; Patterson, Kosson, \& Newman, 1987) proposed that (a) extraverted individuals have an exaggerated focus on reward; that is, when extraverted people are rewarded, they are likely to form dominant response sets that are difficult to interrupt; (b) an increment in arousal is an inevitable consequence of the occurrence of punishment, frustration, or novelty; (c) arousal increases the intensity of whatever response is eventually chosen; and (d) "in contrast to introverts, whose reaction to punishment involves interruption of approach behavior and stimulus processing, extraverts' reaction to punishment, as a result of their more persistent response set for reward, is invigoration of their original goal-directed behavior" (Patterson et al,, 1987, p. 568). This paradoxical response facilitation prevents extraverted individuals from adequately processing the cues for punishment, thus maintaining their deficit in interrupting dominant response sets. Newman and his colleagues (Newman, Wi- dom, \& Nathan, 1985; Patterson et al., 1987) have presented evidence of passive avoidance deficits among extraverted individuals that is consistent with their hypothesis that extraverted people have an exaggerated focus on reward; however, they have not yet undertaken the important theoretical step of explaining why extraverted people have such an exaggerated focus in the first place.

Although there is considerable overlap between Newman's theory and Gray's, there are also important differences. First, Newman emphasized the role of a dominant response set "as the critical factor mediating their [extraverted people's] inhibitory failures" (Newman, Kosson, \& Howland, 1985, p. 20). Second, Newman believes that extraverted people's " insensitivity to punishment' is simply a consequence of the persistence of their approach behavior" (Newman, Kosson, \& Howland, 1985, p. 20). Thus, Newman explained I/E as arising from a hypersensitivity to reward, and predicted that extraverted individuals will only display passive avoidance deficits in situations in which they are also rewarded for responding. On the other hand, Gray explained $\mathrm{I} / \mathrm{E}$ as arising not from the balance of sensitivity to rewards and punishments, but rather from the balance of sensitivity to cues for reward and cues for punishment. This is an important distinction, because within Gray's theory, cues for reward include both cues for approach behavior (reward for responding) and cues for active avoidance (avoid punishment by responding). Similarly, for Gray cues for punishment included both cues for passive avoidance (punishment for responding) and cues for omission or extinction (nonreward for responding). Thus, in contrast to Newman, Gray would predict an extravert deficit at inhibiting responses to cues for punishment even on a task that does not involve reward for responding (e.g., learning to discriminate active avoidance cues from passive avoidance cues) or that involves reward for both responding and not responding (e.g., discriminating between approach cues and omission cues).

One additional but important dimension along which these four theories differ is with respect to the range of applicability of each theory. Clearly, the theories of K. W. Spence (1964) and H. J. Eysenck have been applied to a broader range of conditioning phenomenon than have the theories of Gray and Newman. The theories of Eysenck and Spence were both originally formulated in relation to classical conditioning. However, both Eysenck (H. J. Eysenck \& Eysenck, 1985) and the Spences expanded their original theories to include more complex tasks such as instrumental learning tasks. On the other hand, although the theories of Gray and Newman are clearly applicable to instrumental learning, neither Gray nor Newman have explicitly made predictions regarding classical conditioning.

Each of these theories of conditioning has been developed to explain phenomena within a specified domain of behavior. No theory holds under all possible conditions, but rather within a range of parameter values. Thus, there are two alternative strategies to test theory: The first is to delineate the boundary conditions for a specific theory; the other is to choose phenomena

\footnotetext{
${ }^{4}$ To the extent that highly impulsive individuals are extraverted, it is predicted that they should show poor conditionability under the appropriate conditions. To the extent that highly anxious individuals are introverted, they should condition readily.
} 
relevant to several alternative theories in order to compare the adequacy of their predictions against each other.

As an example of the first strategy, a strong test of Eysenck's theory would require examining whether physiological manipulations of arousal (e.g., caffeine or time of day) interact with I/ $E$, reinforcement frequency, stimulus intensity, and conditioned stimulus-unconditioned stimulus interval. However, an arousal manipulation would be irrelevant from the perspectives of the Spence, Gray, and Newman theories and thus would not provide a test of them.

As we have discussed, a great deal of work has been done identifying the limits of each of these four theories (H. J. Eysenck, 1965; Gray, 1982; Newman, Widom, \& Nathan, 1985; J. T. Spence \& Spence, 1966). It is clear from this work that although each theory addresses some unique and important phenomena, all four make predictions regarding instrumental discrimination learning.

As our intent was to pit these four theories against each other in a paradigm in which they make different predictions, we decided to use an instrumental discrimination learning paradigm. Some critics might argue that a classical conditioning paradigm would provide a fairer test of the Eysenck and Spence theories, as these theories were originally formulated in relation to classical conditioning. Although such a strategy might have resulted in a fairer test of the Eysenck and Spence theories, it would not have permitted us to test the Gray and Newman theories at all. Our choice of an instrumental paradigm allowed us to test hypotheses derived from the later extensions of the Eysenck and Spence theories that are relevant to instrumental conditioning, in addition to testing hypotheses derived from the Gray and Newman theories.

\section{Overview}

The major purpose of the four experiments was to test the following hypotheses regarding each theory:

1. Spence. On a stressful or ego-involving task that involves intratask response competition, (a) Anx should be positively related to performance of correct responses that are initially strong; (b) in the early stages of a task, Anx should be negatively related to performance of correct responses that are weak; and (c) in the later stages of a task, Anx should be positively related to performance of correct responses that were initially weak.

2. Eysenck. Under conditions of low to moderate levels of arousal, introverted individuals will condition better than extraverted individuals.

3. Gray. With regard to $I / E$ and $S / N$, (a) introverted individuals will condition better (learn to respond less) to signals of punishment than will extraverted individuals (passive avoidance, omission, or extinction); (b) extraverted individuals will condition better (learn to respond more) to signals of reward than will introverted individuals (approach and active avoidance); and (c) neurotic individuals will condition better than stable individuals. With regard to Imp and Anx; (d) highly anxious individuals will condition better (learn to respond less) to signals of punishment than will less anxious individuals, and Anx should be unrelated to performance in response to signals of reward; and (e) highly impulsive individuals will condition better (learn to respond more) to signals of reward than will less impulsive individuals, and Imp should be unrelated to performance in response to signals of punishment.

4. Newman. On an instrumental discrimination learning task in which both correct responding and correct response inhibition are rewarded, there should be no differences in performance between extraverted and introverted individuals.

\section{Discrimination Learning Task}

We devised a go-no-go discrimination learning task for this investigation such that the four models made different predictions regarding performance on the task. The task consisted of four different instrumental learning operations among which the subjects had to discriminate. On approach (Ap) trials, the discriminative cue signaled that the response, $R$, would result in reward. On active avoidance (AA) trials, the discriminative cue signaled that $R$ would result in the avoidance of punishment. On omission training $(\mathrm{Om})$ trials, the discriminative cue signaled that withholding $\mathbf{R}$ would result in reward. Finally, on passive avoidance (PA) trials, the discriminative cue signaled that withholding $R$ would result in the avoidance of punishment. Gray (1982) labeled the discriminative cues used in the Ap and AA trials signals for reward; he called those used in the Om and PA trials signals for punishment. We believe that these labels are likely to produce misunderstandings among other researchers as signals for reward may be confused easily with reward itself, and signals for punishment may likewise be confused with punishment itself. To avoid this source of confusion, we prefer to call the cues used in the Ap and AA conditions go cues, as they signal that responding is appropriate. Similarly, we prefer to call the cues used in the Om and PA conditions no-go cues, as they signal that response inhibition is appropriate. Thus, the four types of trials used in the task resulted from the crossing of cue type (go vs. no go) with reinforcement type (reward vs. punishment).

\section{Experiments 1-4}

In the next section of this article we report the results from four experiments designed to test the hypotheses we have outlined. In view of the evidence that individual differences in diurnal arousal patterns are related to Imp (e.g., Revelle, Humphreys, Simon, \& Gilliland, 1980), we varied time of day systematically across the four experiments in order to test the robustness of the relation of personality and conditioning with respect to diurnal arousal patterns. A second variable that was systematically varied across the four experiments was the strength of a dominant response set induction. This variable was manipulated as both Newman (Newman, Widom, \& Nathan, 1985) and Barratt (1972) emphasized the role of a dominant response set in producing behavioral effects that are related to, respectively, I/E and Imp. Finally, we also varied task difficulty systematically across the four experiments, as the earlier literature indicated that Anx may interact with task difficulty (M. W. Eysenck, 1981). Distractor stimuli were used in the difficult version of the task, but not in the easy version. Table 1 shows the values of each of these three parameters for each of the four studies. 
Table 1

Experimental Conditions Used in Experiments 1-4

\begin{tabular}{cccc}
\hline Experiment & Time of day & $\begin{array}{c}\text { Strength of dominant } \\
\text { response set induction }\end{array}$ & Difficulty \\
\hline 1 & A.M. & S & H \\
2 & P.M. & S & H \\
3 & P.M. & W & H \\
4 & P.M. & W & E \\
\hline
\end{tabular}

Note. $\mathrm{S}=$ strong, $\mathrm{W}=$ weak, $\mathrm{H}=$ hard, $\mathrm{E}=$ easy.

\section{Method}

\section{General Procedure}

Each of the four experiments was conducted in group sessions with between 1 and 4 subjects per session. The subjects were greeted by a male experimenter wearing a white lab coat and were then asked to sign a consent form. To induce ego-involvement, the consent form stated that the subject would be taking a "test of learning ability" that would be difficult and frustrating and that the experimenter would observe their performance on the task. After the consent forms were signed, the personality questionnaires were administered. After either all of the subjects had finished the personality questionnaires or $20 \mathrm{~min}$ had passed, subjects were given instructions for the discrimination task and seven practice trials. When all of the subjects indicated that they understood the instructions and the practice trials were reviewed the discrimination task was administered. During the discrimination task, the experimenter stood behind the subjects, observing the subjects' performance, and took notes on their behavior. In Experiment 1, an additional performance task was included at the conclusion of the discrimination task. The results from this additional task are not discussed in this article.

\section{Materials}

Personality measures. The personality questionnaires administered included the following: (a) the Eysenck Personality Inventory (EPI; H. J. Eysenck \& Eysenck, 1975a), which includes 24 I/E items, 24 S/N items, and 9 lie items (within the I/E scale there are subscales for Imp and sociability, see Revelle et al., 1980); and (b) the A-Trait scale from the State-Trait Anxiety Inventory (STAI; Spielberger, Gorsuch, \& Lushene, 1970). In addition, there were several other personality questionnaires given in Experiment 1; the results from these additional questionnaires are not discussed in this article.

Discrimination learning task. The stimuli used were capital letters, which were displayed on the screen of a Macintosh computer. In the difficult version of the task, a pair of letters made up of one discriminative cue and one distractor letter was presented on each trial with the discriminative cue's position within the letter pair randomized. In the easier version of the task, a single discriminative cue was presented on each trial. A total of eight discriminative stimuli were used, two for each trial type. Thus, there were four go cues (two for Ap and two for AA) and four no-go cues (two for Om and two for PA). A different set of eight letters was used as distractors in the difficult version of the task, and these distractors, as well as the eight letters used as discriminative stimuli, were randomly chosen for each subject. The response alternatives to these stimuli were either to press or not press the "mouse button." Reinforcement consisted of winning or losing points that subjects were told were a measure of their "learning ability." A continuous reinforcement schedule was used, and feedback was provided in two forms: (a) by statements displayed on the computer screen, such as "You won I point" and "Your total is 23 points," and (b) by a line graph that rose when points were won and fell when points were lost.

The stimuli were presented in a block-randomized order in blocks of 16. The entire task consisted of a total of 10 blocks, or 160 trials. Stimuli were presented on the screen for $2 \mathrm{~s}$, and feedback was presented during interstimuli presentation intervals. The intertrial time interval, and hence the duration of feedback, varied randomly between $1.5-2.5 \mathrm{~s}$. We used a pretreatment manipulation involving an increased probability of a go cue to establish a dominant response set to press the button from the task's outset.

\section{Experiment 1}

Subjects. The subjects were 122 students from the introductory psychology class at Northwestern University. They served in the experiment as part of a course requirement.

Design and procedure. Each subject was tested at 9:00, 10:00, or 11:00 A.M., using the standard discrimination task with distractor letters. The pretreatment manipulation consisted of a total of 32 trials, of which 28 contained go cues ( 26 Ap cues and 2 AA cues). Thus, the probability of a go cue during the dominant response set induction was .88 (the probability of a reward for responding was .81 ).

\section{Experiment 2}

Subjects. The subjects were $\mathbf{5 2}$ students from the same source as used in Experiment 1.

Design and procedure. Each subject was tested at 4:00, 5:00, 6:00, 7:00, or 8:00 P.M. The discrimination task and pretreatment manipulation were identical to those used in the Experiment 1.

\section{Experiment 3}

Subjects. The subjects were 100 students from the same source as used in Experiments 1 and 2.

Design and procedure. Each subject was tested at 4:00, 5:00, 6:00, 7:00, or 8:00 P.M. The discrimination task was identical to that used in Experiments 1 and 2. The pretreatment manipulation consisted of 50 trials, of which 30 contained go cues ( 20 Ap cues and $10 \mathrm{AA}$ cues). Thus, the probability of a go cue during the dominant response set induction was .60 (the probability of a reward for responding was .40 ).

\section{Experiment 4}

Subjects. The subjects were 36 students from the same source as used in Experiments 1-3.

Design and procedure. Each subject was tested at 6:00, 7:00, or 8:00 P.M. The discrimination task was identical to that used in Experiments 1-3 except that distractors were not used; that is, the discriminative cues were presented by themselves. The pretreatment manipulation was identical to that used in Experiment 3 except that distractors were not used.

\section{Results}

For all four experiments, we computed the slope of the linear regression of the number of presses (on the mouse button) on

\footnotetext{
${ }^{5}$ The variations in sample size across the four experiments reflect idiosyncrasies in the availability of subjects during each of the quarters in which the experiments were conducted.
} 
trial blocks for each of the four types of trials (Ap, AA, Om, PA) for each subject. ${ }^{6}$ The hypotheses derived from each of the four models of personality and conditioning were tested by two (I/E and S/N or Imp and Anx) $2 \times 2 \times 2 \times 2$ (I/E or Imp $\times \mathrm{S} / \mathrm{N}$ or Anx $\times$ Cue Type $\times$ Reinforcement Type) repeated measures analyses of variance (ANOVAS) with the slope of the linear regression of the number of presses on trial blocks as the dependent variable for both analyses. In each experiment, subjects were divided into groups of extraverted and introverted individuals and stable and neurotic individuals by taking a median split of the scores on the Extraversion (I/E) and Neuroticism (S) N) scales from the EPI. Similarly, the subjects in each experiment were divided into groups of high and low impulsive and high and low anxious by taking a median split of the scores on the Impulsivity subscale (of the Extraversion Scale) from the EPI and the A-Trait (Anx) scale from the STAI. The level of statistical significance adopted for these experiments was $p \leq .05$.

\section{Experiment 1}

Experiment 1 was conducted in the morning and used distractor stimuli. The probability of a go cue during the pretreatment manipulation was 88 .

Situational variables. The cue-type effect was significant, $F(1,118)=65.66\left(M S_{\mathrm{e}}=0.73\right)$. As expected, the slope of the linear regression of the number of presses on blocks was positive for go cues $(\beta=0.60)$ and negative for no-go cues $(\beta=-0.70)$. There was also a significant effect of reinforcement type, $F(1$, $118)=15.66\left(M S_{\mathrm{e}}=0.61\right)$. The slope of the linear regression of the number of presses on blocks was positive when reward was used $(\beta=0.24)$ and negative when punishment was used $(\beta=-0.34)$. This unexpected effect seems less puzzling when we consider that reward appeared to be more effective at reinforcing go responses (Ap, $\beta=0.40$ ) than no-go responses $(\mathrm{Om}$, $\beta=-0.16$ ), whereas the avoidance of punishment appeared to be more effective at reinforcing no-go responses ( $\mathrm{PA}, \beta=-0.54$ ) than go responses (AA, $\beta=0.20$ ).

Effects involving personality variables. The Reinforcement Type $\times \mathrm{S} / \mathrm{N}$ interaction was significant, $F(1,118)=4.42$ $\left(M S_{\mathrm{e}}=0.60\right)$. The stable individuals showed a greater increase than neurotic individuals in their response rates over blocks when reward was used ( $\beta s=0.42$ vs. 0.03 ), and the stable individuals also showed a greater decrease than neurotic individuals in their response rates over blocks when punishment was used $(\beta \mathrm{s}=-0.42$, vs -0.25$)$.

The Cue Type $\times \operatorname{Imp} \times$ Anx interaction was significant $F(1$, $118)=7.30\left(M S_{\mathrm{e}}=0.73\right.$; see Figure 1). Among the low impulsive individuals, the simple Cue Type $\times$ Anx interaction was significant, $F(1,67)=4.65\left(M S_{\mathrm{e}}=0.72\right)$, as high anxiety facilitated the learning of the go-no-go discrimination. The simple Cue Type $\times$ Anx interaction approached significance, $F(1$, $51)=2.89\left(M S_{\mathrm{e}}=0.75, p<.10\right)$, and was in the opposite direction among the high impulsive individuals, as high anxiety hindered the learning of the same discrimination among those individuals.

\section{Experiment 2}

As in Experiment 1, in Experiment 2 we used distractor stimuli and the same pretreatment manipulation. Unlike Experiment 1, Experiment 2 was conducted in the afternoon.

Situational variables. The effect of cue type was significant, $F(1,48)=14.64\left(M S_{\mathrm{e}}=0.80\right)$. As expected and as was found in Experiment 1, the slope of the linear regression of the number of presses on blocks was positive for go cues $(\beta=0.31)$ and negative for no-go cues $(\beta=-0.63)$.

Effects involving personality variables. There were no significant main effects or interactions involving any of the personality variables.

\section{Experiment 3}

As in Experiment 2, Experiment 3 used distractor stimuli and was conducted in the afternoon. In Experiment 3, the probability of a go cue during the pretreatment manipulation was smaller than in Experiments 1 and 2 in an attempt to induce a weaker dominant response set.

Situational variables. The cue-type effect was significant, $F(1,96)=60.16\left(M S_{\mathrm{c}}=0.61\right)$. As expected and as was found in Experiments 1 and 2, the slope of the linear regression of the number of presses on blocks was positive for go cues $(\beta=0.39)$ and negative for no-go cues $(\beta=-0.86)$. There was also a significant effect of reinforcement type, $F(1,96)=4.74\left(M S_{\mathrm{e}}=\right.$ $0.67)$. Whereas the slope of the linear regression of the number of presses on blocks was close to zero when reward was used $(\beta=-0.06)$, it was negative when punishment was used $(\beta=$ -0.41). As was the case in Experiment 1, the unexpected finding of a negative slope when punishment was used appears to have resulted from the avoidance of punishment being more effective at reinforcing no-go responses $(\mathrm{PA}, \beta=-0.54)$ than go responses (AA, $\beta=0.12$ ).

Effects involving personality variables. The interaction of Cue Type $\times$ Reinforcement Type $\times \mathrm{S} / \mathrm{N}$ was significant, $F(1$, $96)=5.48\left(M S_{\mathrm{e}}=0.70\right.$; see Table 2). Table 2 indicates that stable individuals learned faster than high neurotic individuals when reward was used, whereas the opposite pattern was true when punishment was used: the high neurotic individuals learned faster than the stable individuals.

There was a significant Cue Type $\times \operatorname{Imp} \times$ Anx interaction, $F(1,96)=3.89\left(M S_{\mathrm{e}}=0.61\right.$; see Figure 2$)$. The simple Cue Type $\times$ Anx interaction approached significance, $F(1,51)=$ $3.02\left(M S_{\mathrm{e}}=0.50, p<.10\right)$ among the low impulsive individuals. As was found in Experiment 1, high anxiety facilitated the learning of the go-no-go discrimination among the low impulsive individuals. Similar to Experiment 1's results, the simple Cue Type $\times$ Anx interaction was in the opposite direction among the high impulsive individuals, as high anxiety hindered the learning of the identical discrimination among those individuals. Unlike Experiment 1 , the simple Cue Type $\times$ Anx in-

\footnotetext{
${ }^{6}$ Before the linear regressions were computed, we collapsed the data into four blocks. Thus, the first block represents the first 10 presentations of each trial type, the second block represents the next 10 presentations of each trial type, etc. The raw means and standard deviations for each block are available from Richard Zinbarg.
} 
Low Imp

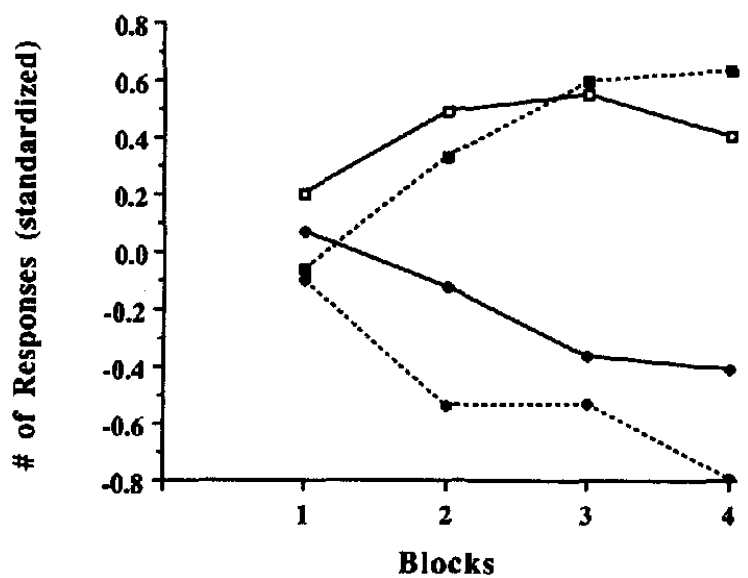

High Imp

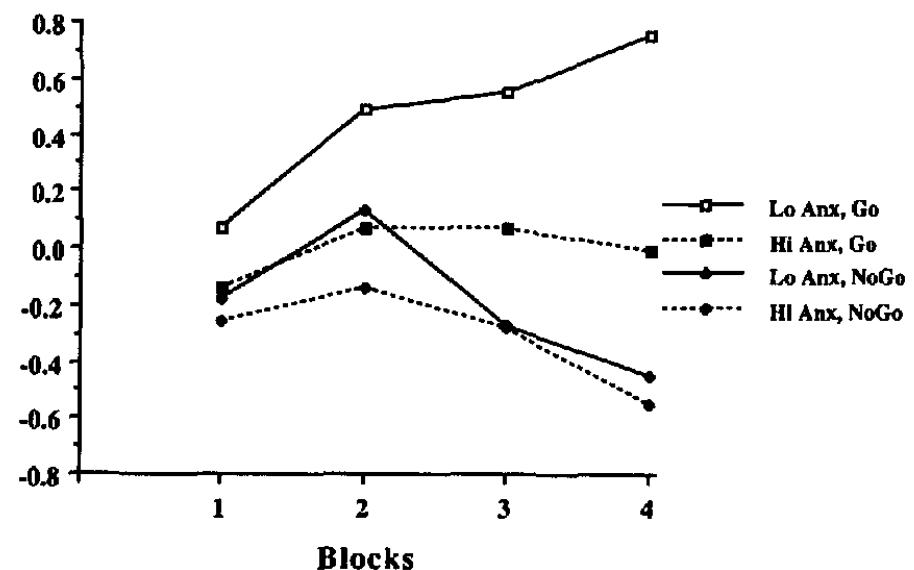

Figure 1. Standardized number of responses as a function of cue type, impulsivity (Imp), anxiety (Anx), and trial blocks: Experiment 1.

teraction did not approach significance among the high impulsive individuals.

\section{Experiment 4}

Experiment 4 was conducted in the afternoon, as were Experiments 2 and 3, and used the same pretreatment manipulation as in Experiment 3. Unlike each of the three preceding experiments, Experiment 4 did not use distractor stimuli.

Situational variables. The effect of cue type was significant, $F(1,32)=86.70\left(M S_{e}=0.58\right)$. As we expected and as was found in each of the previous experiments, the slope of the linear regression of the number of presses on blocks was positive for go cues $(\beta=1.04)$ and negative for no-go cues $(\beta=-1.53)$. There was also a significant effect of reinforcement type, $F(1,32)=$ $11.79\left(M S_{\varepsilon}=0.66\right)$. This effect was moderated by a significant Cue Type $\times$ Reinforcement Type interaction $F(1,32)=11.79$ $\left(M S_{c}=0.66\right)$. The slope of the linear regression of the number of presses on blocks for go cues was larger when punishment

Table 2

Slope of the Linear Regression of the Number of Responses on Blocks as a Function of Cue Type, Reinforcement

Type, and Neuroticism: Experiment 3

\begin{tabular}{lrr}
\hline & \multicolumn{2}{c}{ Neuroticism } \\
\cline { 2 - 3 } Cue type & Low & High \\
\hline & Reward & \\
Go & 0.41 & 0.13 \\
Nogo & -0.39 & -0.27 \\
& & \\
& Punishment & \\
Go & 0.09 & 0.16 \\
Nogo & -0.40 & -0.67 \\
\hline
\end{tabular}

was used (AA, $\beta=0.74$ ) than when reward was used (Ap, $\beta=$ 0.31 ), whereas the slope of the linear regression for no-go cues was much more negative when punishment was used (PA, $\beta=$ $-1.10)$ than when reward was used (Om, $\beta=-0.44)$.

Effects involving personality variables. The $\mathrm{S} / \mathrm{N} \times \mathrm{I} / \mathrm{E}$ interaction was significant, $F(1,32)=6.14\left(M S_{e}=0.67\right)$. Neurotic introverted individuals showed a decrease in the number of button presses as a function of blocks $(\beta=-0.28)$, whereas stable introverted individuals did not show much of a change in the number of button presses as a function of blocks $(\beta=0.04)$. In contrast to this pattern, neurotic extraverted individuals showed an increase in the number of button presses as a function of blocks $(\beta=0.12)$, whereas stable extraverted individuals showed a decrease in the number of button presses as a function of blocks $(\beta=-0.25)$.

The Reinforcement Type $\times \mathrm{S} / \mathrm{N} \times \mathrm{I} / \mathrm{E}$ interaction was also significant, but was difficult to interpret, $F(1,32)=4.75\left(M S_{\mathrm{e}}=\right.$ 0.63 ; see Table 3 ).

The Cue Type $\times$ Anx interaction was significant $F(1,32)=$ $5.77\left(M S_{e}=0.57\right)$, and whereas there was little difference in the rates at which the low anxious $(\beta=1.06)$ and high anxious subjects $(\beta=1.03)$ learned to press to go cues, the low anxious subjects learned to inhibit responses to no-go cues at a much faster rate $(\beta=-2.02)$ than did the high anxious subjects $(\beta=$ $-1.03)$.

\section{Psychometric Results}

Table 4 shows the mean and median I/E, S/N, Imp, and Anx scores; the standard deviations of these scores; and the reliability of these scales (as estimated both by Cronbach's $\alpha, 1951$, and Revelle's 8,1979 ) for Experiments 1-4. The differences among the experiments in the statistics reported in Table 4 are relatively small and appear to be largely unrelated to the magnitude of the observed effects of personality on discrimination task performance.

Table 5 shows the intercorrelations among the Imp, Anx, I/ 
Low Imp

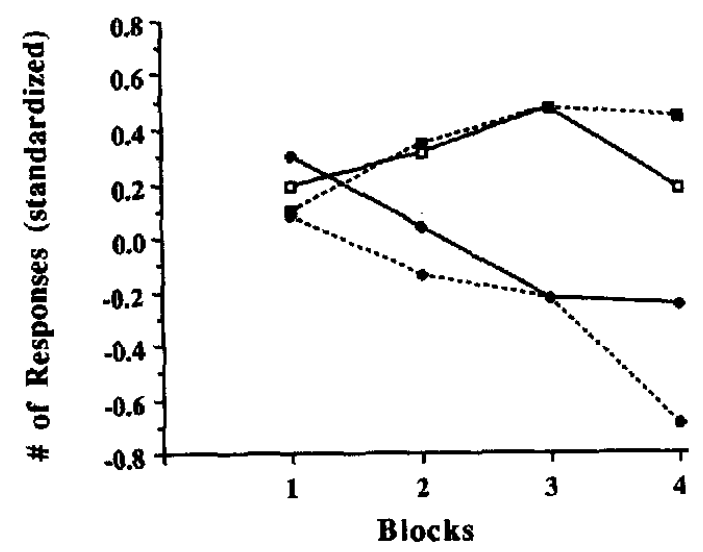

High Imp

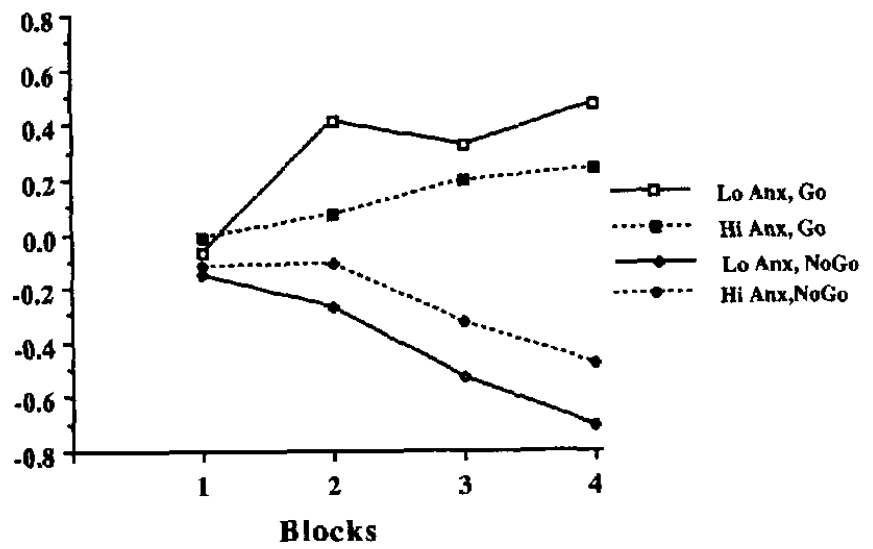

Figure 2. Standardized number of responses as a function of cue type, impulsivity (Imp), anxiety (Anx), and trial blocks: Experiment 3.

E, and S/N scales for Experiments 1-4. Due to item overlap (all nine items on the Imp scale are taken from the EPI Extraversion $[\mathrm{I} / \mathrm{E}]$ scale), the correlation between $\mathrm{Imp}$ and $\mathrm{I} / \mathrm{E}$ is meaningless and is not included in this table. The most striking feature of Table 5 is the consistent pattern of very high correlations between Anx and S/N and of smaller, negative correlations between $A n x$ and $I / E$.

\section{Discussion}

\section{Consistencies Between Experiments}

Taken together, these four experiments show consistent patterns for the personality variables of Imp and Anx. The Cue Type $\times$ Imp $\times$ Anx interaction was the only effect containing personality variables that was statistically significant in more than one of the experiments: It was significant in both Experiment 1 and Experiment 3. Moreover, the patterns of the Cue Type $\times$ Imp $\times$ Anx data found in Experiments 2 and 4 are similar to the patterns found in Experiments 1 and 3. Table 6 summarizes the Cue Type $\times$ Imp $\times$ Anx data for each of the four experiments. In each experiment, high anxiety hindered learning to a greater extent among the high impulsive individuals than among the low impulsive individuals. On the other hand, in Experiments 1 and 3, high anxiety actually facilitated learning among the low impulsive individuals. Given the consistency of the results across the four experiments, it would appear that the Cue Type $\times \operatorname{Imp} \times$ Anx interaction is robust with respect to variations in the time of day, the strength of a dominant response set, and task difficulty. The failure to find an interaction with time of day seems particularly significant as it suggests that the cue type $\times$ Imp $\times$ Anx effect is not related to arousal as many other impulsivity-related performance effects seem to be (e.g., Revelle et al., 1980).

Given that Imp is a subscale of $\mathrm{I} / \mathrm{E}$ and the high correlations between $A n x$ and $S / N$, it might seem reasonable to regard $L / E$ as being identical to Imp and $\mathrm{S} / \mathrm{N}$ as being identical to Anx. This line of reasoning raises questions regarding whether Imp and $A n x$ are better predictors than $\mathrm{I} / \mathrm{E}$ and $\mathrm{S} / \mathrm{N}$ of individual differences in instrumental discrimination learning. First, is the pattern of results for $\mathrm{I} / \mathrm{E}$ and $\mathrm{S} / \mathrm{N}$ similar to the pattern displayed by Imp and Anx? Second, is there a significant increment in variance explained by Imp and Anx beyond that explained by $\mathrm{I} / \mathrm{E}$ and $\mathrm{S} / \mathrm{N}$ ?

To address the question regarding the similarity of the results for $I / E$ and $S / N$ to those for Imp and Anx, we summarize in Table 7 the Cue Type $\times 1 / E \times S / N$ data for each of the four experiments. In three of the four experiments, (Experiments 1 , 3 , and 4), the pattern of results for $\mathrm{I} / \mathrm{E}$ and $\mathrm{S} / \mathrm{N}$ is similar to that we have described for Imp and Anx. In these three experiments, $\mathrm{S} / \mathrm{N}$ hindered learning to a greater extent among the extraverted

Table 3

Slope of the Linear Regression of the Number of Standardized Responses as a Function of Reinforcement Type, Extraversion, and Neuroticism: Experiment 4

\begin{tabular}{|c|c|c|c|c|}
\hline \multirow[b]{2}{*}{ Reinforcement } & \multicolumn{2}{|c|}{ Low extraversion } & \multicolumn{2}{|c|}{ High extraversion } \\
\hline & $\begin{array}{c}\text { Low } \\
\text { neuroticism }\end{array}$ & $\begin{array}{c}\text { High } \\
\text { neuroticism }\end{array}$ & $\begin{array}{c}\text { Low } \\
\text { neuroticism }\end{array}$ & $\begin{array}{c}\text { High } \\
\text { neuroticism }\end{array}$ \\
\hline $\begin{array}{l}\text { Reward } \\
\text { Punishment }\end{array}$ & $\begin{array}{r}0.55 \\
-0.40\end{array}$ & $\begin{array}{l}-0.59 \\
-0.52\end{array}$ & $\begin{array}{l}-0.72 \\
-0.27\end{array}$ & $\begin{array}{r}0.69 \\
-0.20\end{array}$ \\
\hline
\end{tabular}


Table 4

Means, Medians, Standard Deviations, and Reliabilities of Extraversion, Neuroticism. Impulsivity, and Anxiety Scales: Experiments 1-4

\begin{tabular}{|c|c|c|c|c|}
\hline \multirow[b]{2}{*}{ Statistic } & \multicolumn{4}{|c|}{ Experiment } \\
\hline & 1 & 2 & 3 & 4 \\
\hline \multicolumn{5}{|c|}{ Extraversion } \\
\hline $\begin{array}{l}M \\
M d n \\
S D \\
\alpha \\
\beta\end{array}$ & $\begin{array}{r}13.22 \\
14.00 \\
3.91 \\
.74 \\
.11\end{array}$ & $\begin{array}{r}14.21 \\
14.00 \\
3.83 \\
.75 \\
.26\end{array}$ & $\begin{array}{r}13.83 \\
15.00 \\
3.95 \\
.73 \\
.11\end{array}$ & $\begin{array}{r}14.03 \\
14.00 \\
3.08 \\
.69 \\
.12\end{array}$ \\
\hline \multicolumn{5}{|c|}{ Neuroticism } \\
\hline $\begin{array}{l}M \\
M d n \\
S D \\
\alpha \\
\beta\end{array}$ & $\begin{array}{r}8.14 \\
8.00 \\
4.65 \\
.83 \\
.43\end{array}$ & $\begin{array}{r}9.98 \\
10.00 \\
4.16 \\
.79 \\
.12\end{array}$ & $\begin{array}{r}9.40 \\
8.00 \\
4.78 \\
.83 \\
.11\end{array}$ & $\begin{array}{r}9.92 \\
9.00 \\
4.89 \\
.85 \\
.28\end{array}$ \\
\hline \multicolumn{5}{|c|}{ Impulsivity } \\
\hline $\begin{array}{l}M \\
M d n \\
S D \\
\alpha \\
\beta\end{array}$ & $\begin{array}{r}4.16 \\
4.00 \\
1.82 \\
.52 \\
.17\end{array}$ & $\begin{array}{r}4.52 \\
4.00 \\
1.65 \\
.50 \\
.04\end{array}$ & $\begin{array}{r}4.59 \\
4.00 \\
1.72 \\
.46 \\
.07\end{array}$ & $\begin{array}{r}4.61 \\
5.00 \\
1.63 \\
.68 \\
.41\end{array}$ \\
\hline \multicolumn{5}{|c|}{ Anxiety } \\
\hline $\begin{array}{l}M \\
M d n \\
S D \\
\alpha \\
\beta\end{array}$ & $\begin{array}{r}36.78 \\
35.00 \\
10.25 \\
.91 \\
.55\end{array}$ & $\begin{array}{r}38.00 \\
37.00 \\
8.15 \\
.86 \\
.32\end{array}$ & $\begin{array}{r}38.26 \\
38.00 \\
9.44 \\
.89 \\
.66\end{array}$ & $\begin{array}{r}36.61 \\
35.50 \\
8.29 \\
.86 \\
.50\end{array}$ \\
\hline
\end{tabular}

than the introverted individuals. However, the opposite pattern of results is found in Experiment 2, as S/N hindered learning to a greater extent among the introverted than the extraverted individuals. Another dissimilarity between the results for $\mathrm{I} / \mathrm{E}$ and $S / N$ as compared with those for Imp and AnX is found in Experiment 3. In Experiment 3, S/N did not facilitate learning among the introverted individuals as high anxiety did among the low impulsive individuals. Thus, it seems that the results for I/E and $S / N$ and those for Imp and Anx are similar in their overall pattern. However, the results for $\mathrm{I} / \mathrm{E}$ and $\mathrm{S} / \mathrm{N}$ are not as consistent as, and are in some ways dissimilar to, those for Imp and Anx.

To address the question regarding the incremental validity of the Imp and Anx scales, we reanalyzed the data from Experiments 1 and 3, using both pairs of personality traits as grouping factors in $2(\mathrm{I} / \mathrm{E}) \times 2(\mathrm{~S} / \mathrm{N}) \times 2$ (Imp) $\times 2$ (Anx) $\times 2$ (cue type) $\times$ 2 (reinforcement type) repeated measures aNOVAs. We included tests of all effects except those involving an interaction of either Imp or Anx with either I/E or S/N. By partialing out the variance due to the effects that included either $I / E$ or $S / N$, as well as the effects that included the interaction of these two variables, these analyses enabled us to ascertain whether there was a significant increment in variance explained by Imp and Anx beyond that explained by $I / E$ and $S / N$. In both of these analyses, the Cue Type $\times$ Imp $\times$ Anx interaction was significant: Experiment $1, F(1,115)=6.39\left(M S_{e}=1.49\right)$; Experiment $3, F(1,93)=5.94\left(M S_{\mathrm{e}}=1.18\right)$. In contrast, the Cue Type $\times I /$ $\mathrm{E} \times \mathrm{S} / \mathrm{N}$ interaction was not significant in either of these analyses. These results provide evidence that, in Experiments 1 and 3 , the Cue Type $\times \operatorname{Imp} \times$ Anx interaction does account for a significant increment in the variance explained beyond that explained by $\mathrm{I} / \mathrm{E}$ and $\mathrm{S} / \mathrm{N}$. Therefore, despite the temptation to regard $\mathrm{I} / \mathrm{E}$ as being identical to Imp and $\mathrm{S} / \mathrm{N}$ as being identical to Anx, it seems clear that individual differences in instrumental discrimination learning are more consistently and strongly associated with Imp and Anx than with $\mathrm{I} / \mathrm{E}$ and $\mathrm{S} / \mathrm{N}$.

\section{Relative Efficacy of the Four Models}

Given that there were consistent patterns in the data, it is appropriate to ask to what extent they support or refute the alternative hypotheses that we derived and tested. The pattern of results predicted by several of these hypotheses are complex, and the data did not provide unequivocal support for any of them. Therefore, for each of the four theories, we describe each prediction made by that theory and whether that prediction was supported by the data.

Spence's theory. Aspects of the Cue Type $\times \operatorname{Imp} \times$ Anx data support Spence's model, whereas other aspects of this data contradict it. According to Spence's Hypothesis a, high anxiety should facilitate responding to the go cues in this paradigm as the pretreatment manipulation established responding as the

Table 5

Intercorrelations of Extraversion, Neuroticism, Impulsivity, and Anxiety: Experiments 1-4

\begin{tabular}{|c|c|c|c|c|}
\hline Scale & 1 & 2 & 3 & 4 \\
\hline \multicolumn{5}{|c|}{ Experiment 1} \\
\hline $\begin{array}{l}\text { 1. Extraversion } \\
\text { 2. Neuroticism } \\
\text { 3. Impulsivity } \\
\text { 4. Anxiety }\end{array}$ & $\begin{array}{c}\overline{.03} \\
\frac{-.16}{-}\end{array}$ & $\begin{array}{l}-18 \\
.75\end{array}$ & $-\overline{-05}$ & - \\
\hline \multicolumn{5}{|c|}{ Experiment 2} \\
\hline $\begin{array}{l}\text { 1. Extraversion } \\
\text { 2. Neuroticism } \\
\text { 3. Impulsivity } \\
\text { 4. Anxiety }\end{array}$ & $\begin{array}{l}-.41 \\
-.51\end{array}$ & -.16 & $-\overline{-29}$ & - \\
\hline \multicolumn{5}{|c|}{ Experiment 3} \\
\hline $\begin{array}{l}\text { 1. Extraversion } \\
\text { 2. Neuroticism } \\
\text { 3. Impulsivity } \\
\text { 4. Anxiety }\end{array}$ & $\begin{array}{l}-.34 \\
-.40 \\
\end{array}$ & $\begin{array}{r}-. \\
-.12 \\
.80 \\
\end{array}$ & -.18 & - \\
\hline \multicolumn{5}{|c|}{ Experiment 4} \\
\hline $\begin{array}{l}\text { 1. Extraversion } \\
\text { 2. Neuroticism } \\
\text { 3. Impulsivity } \\
\text { 4. Anxiety }\end{array}$ & $\begin{array}{l}-\overline{-21} \\
\overline{-.25}\end{array}$ & $\begin{array}{l}-19 \\
.88\end{array}$ & $\overline{.09}$ & - \\
\hline
\end{tabular}

Note. The correlations between Extraversion and Impulsivity were meaningless due to item overlap and were therefore omitted. 
dominant response. ${ }^{7}$ Although this prediction is supported by the data for our low impulsive subjects, it is contradicted by the finding that high anxiety hindered responding to the go cues among our high impulsive subjects.

As our pretreatment manipulation established responding as the dominant response, it follows that response inhibition was initially weaker than responding. Thus, Spence's Hypotheses b and $\mathrm{c}$ predict that high anxiety should lead to overresponding to no-go cues in the beginning of the task; however, by the later stages of the task, high anxiety should eventually facilitate response inhibition to no-go cues. Although high anxiety facilitated response inhibition to no-go cues among the low impulsive subjects, it hindered learning of the no-go cues among the high impulsive subjects. This finding contradicts Spence's Hypotheses $\mathrm{b}$ and $\mathrm{c}$.

Eysenck's theory. Assuming that the paradigm used in this investigation did not lead to overarousal among the introverted subjects, then the failure to find reliable effects of $1 / E$ does not provide any support for Eysenck's model. Some might argue that our paradigm did not provide a fair test of Eysenck's theory because we did not use partial reinforcement, one of the conditions thought to lead to moderate levels of arousal. However, we did use a discrimination task and weak unconditioned stimuli, two of the other conditions thought to favor the development of moderate levels of arousal. Moreover, the data reported by H. J. Eysenck and Levey (1972) indicate that partial reinforcement is not as important as the other variables in producing moderate levels of arousal. Thus, we believe our paradigm did provide a fair test of Eysenck's hypotheses regarding instrumental conditioning.

In addition, Eysenck's model assumes that $\mathrm{I} / \mathrm{E}$ and $\mathrm{S} / \mathrm{N}$ are

Table 6

Slope of the Linear Regression of the Number of Responses as a Function of Cue Type, Impulsivity,

and Anxiety: Experiments 1-4

\begin{tabular}{|c|c|c|c|c|}
\hline \multirow[b]{2}{*}{ Experiment } & \multicolumn{2}{|c|}{ Low impulsivity } & \multicolumn{2}{|c|}{ High impulsivity } \\
\hline & Low anxiety & High anxiety & Low anxiety & High anxiety \\
\hline \multicolumn{5}{|c|}{ Go cue } \\
\hline $2^{1}{ }^{1}{ }^{n}{ }^{n}$ & $\begin{array}{l}0.30 \\
36 \\
0.10 \\
13 \\
0.07 \\
25 \\
1.09 \\
12\end{array}$ & $\begin{array}{l}0.99 \\
33 \\
-0.14 \\
15 \\
0.53 \\
28 \\
1.16 \\
13\end{array}$ & $\begin{array}{l}0.90 \\
28 \\
0.75 \\
14 \\
0.61 \\
27 \\
1.00 \\
6\end{array}$ & $\begin{array}{l}0.16 \\
25 \\
0.64 \\
10 \\
0.32 \\
20 \\
0.70 \\
5\end{array}$ \\
\hline \multicolumn{5}{|c|}{ No-go cue } \\
\hline $2^{1}{ }^{n}{ }^{n} n$ & $\begin{array}{c}-0.75 \\
36 \\
-0.70 \\
13 \\
-0.86 \\
25 \\
-1.71 \\
12\end{array}$ & $\begin{array}{c}-0.94 \\
33 \\
-0.57 \\
15 \\
-1.08 \\
28 \\
-1.12 \\
13\end{array}$ & $\begin{array}{c}-0.55 \\
28 \\
-0.76 \\
14 \\
-0.86 \\
27 \\
-2.65 \\
6\end{array}$ & $\begin{array}{c}-0.48 \\
25 \\
-0.45 \\
10 \\
-0.58 \\
20 \\
-0.82 \\
5\end{array}$ \\
\hline
\end{tabular}

Table 7

Slope of the Linear Regression of the Number of Responses as a Function of Cue Type, Extraversion, and Neuroticism: Experiments 1-4

\begin{tabular}{|c|c|c|c|c|}
\hline \multirow[b]{2}{*}{ Experiment } & \multicolumn{2}{|c|}{ Introverted } & \multicolumn{2}{|c|}{ Extraverted } \\
\hline & Stable & Neurotic & Stable & Neurotic \\
\hline \multicolumn{5}{|c|}{ Go cue } \\
\hline $2^{1}{ }^{1}{ }^{n}{ }^{n}$ & $\begin{array}{l}0.46 \\
34 \\
0.74 \\
12 \\
0.54 \\
19 \\
1.73 \\
8 \\
\end{array}$ & $\begin{array}{l}0.86 \\
26 \\
-0.02 \\
15 \\
0.57 \\
30 \\
0.63 \\
10 \\
\end{array}$ & $\begin{array}{c}0.76 \\
31 \\
-0.22 \\
13 \\
0.30 \\
31 \\
0.90 \\
11 \\
\end{array}$ & $\begin{array}{l}0.36 \\
31 \\
0.86 \\
12 \\
0.17 \\
20 \\
1.10 \\
7\end{array}$ \\
\hline \multicolumn{5}{|c|}{ No-go cue } \\
\hline $2^{1}{ }^{n}{ }^{n}$ & $\begin{array}{c}-0.71 \\
34 \\
-0.84 \\
12 \\
-0.83 \\
19 \\
-1.58 \\
8\end{array}$ & $\begin{array}{c}-0.90 \\
26 \\
-0.61 \\
15 \\
-0.78 \\
30 \\
-1.74 \\
10\end{array}$ & $\begin{array}{c}-0.50 \\
31 \\
-0.92 \\
13 \\
-0.90 \\
31 \\
-1.89 \\
11\end{array}$ & $\begin{array}{c}-0.74 \\
31 \\
-0.14 \\
12 \\
-0.97 \\
20 \\
-0.61 \\
7\end{array}$ \\
\hline
\end{tabular}

fundamental dimensions and that Imp and Anx are merely secondary. The stronger relations with Imp and Anx than with $\mathrm{I} / \mathrm{E}$ and $\mathbf{S} / \mathrm{N}$ contradict this assumption.

Gray's theory. The failure to find reliable effects of $\mathrm{I} / \mathrm{E}$ and $\mathrm{S} / \mathrm{N}$ in this paradigm provides no support for Gray's Hypotheses a-c. The Cue Type $\times$ Imp $\times$ Anx data provided some supportive evidence, in addition to some disconfirming evidence, for Gray's Hypothesis d. The finding that high anxiety facilitated the learning of no-go cues among low impulsive subjects is consistent with Gray's Hypothesis d. Gray's model is unable, however, to explain the two findings that (a) high anxiety also facilitated learning of go cues among low impulsive subjects, and (b) high anxiety hindered learning of no-go cues among high impulsive subjects. It is difficult to explain either of these finding in terms of the hypothesis that Anx is simply related to sensitivity to no-go cues.

We should also point out that the extremely high correlations between $\mathrm{S} / \mathrm{N}$ and Anx and the smaller correlations between $\mathrm{I} /$ E and Anx and between S/N and Imp suggest that Gray's (1981) original $45^{\circ}$ rotation of $\mathrm{I} / \mathrm{E}$ and $\mathrm{S} / \mathrm{N}$ to produce Imp and Anx is incorrect. The correlations obtained here are consistent with those reported by H. J. Eysenck and Eysenck (1985) and suggest that Anx lies much closer to $\mathrm{S} / \mathrm{N}$ than to $\mathrm{I} / \mathrm{E}$ and that neither Anx nor $\mathrm{S} / \mathrm{N}$ are closely related to Imp. In addition, Rocklin

\footnotetext{
${ }^{\circ}$ Response rates during the pretreatment manipulation equaled $70 \%$, $68 \%, 61 \%$, and $59 \%$ in each of the four experiments, respectively. The response rates during the first block of trials equaled $58 \%, 58 \%, 58 \%$, and $60 \%$ in each of the four experiments, respectively. Thus, it would appear that the pretreatment was successful in establishing responding as the dominant response.
} 
and Revelle (1981) have found that the Extraversion (I/E) scale of the Eysenck Personality Questionnaire (EPQ; H. J. Eysenck \& Eysenck, 1975b) has little relation with Imp and is primarily a measure of sociability. Taken together, the findings reported here and in Rocklin and Revelle (1981) indicate that Imp lies outside of the two-factor plane defined by $1 / \mathrm{E}$ (sociability) as measured by the EPQ and $\mathrm{S} / \mathrm{N}$.

Newman's theory. As both correct responding and correct response inhibition were rewarded in our paradigm, Newman's model would predict that extraverted and introverted subjects would not differ in their response tendencies. Therefore, the failure to find reliable effects of $I / E$ is not inconsistent with Newman's model.

However, as was also true of Eysenck's theory, Newman's model assumes that $\mathrm{I} / \mathrm{E}$ and $\mathrm{S} / \mathrm{N}$ are the fundamental causal dimensions. It is clear that the finding of stronger results for Imp and Anx than for $\mathrm{I} / \mathrm{E}$ and $\mathrm{S} / \mathrm{N}$ does not support this assumption.

\section{Suggested Revision of Gray's Model: The Role of Expectancy in Behavior}

A plausible model that provides a better fit to the Cue Type $X$ Imp $\times$ Anx data is that Imp and Anx interact to produce behavioral activation and inhibition. This model is also consistent with the findings of Barratt (1972; Barratt \& Patton, 1983) that Imp and Anx interact in tasks requiring the ability to modify a dominant response set.

To construct such a model that yields a closer fit to these data, we made the following assumptions:

1. The tendency to engage in a response is some function of the difference between approach motivation and inhibitory motivation (Atkinson, 1957).

2. Motivation is some multiplicative function of expectation and value or sensitivity (Rotter, 1964).

3. Association between stimuli or events results in the formation of expectations. ${ }^{8}$

4. Certain processing resources are devoted to forming associations to aversive events, whereas other resources are devoted to forming associations to appetitive events (Grossberg, 1987; Konorski, 1948; Moore \& Stickney, 1985; Schmajuk \& Moore, 1986; Wagner \& Larew, 1985).

5. These aversive and appetitive resources are mutually inhibitory (Grossberg, 1987; Konorski, 1948; Moore \& Stickney, 1985; Schmajuk \& Moore, 1986; Wagner \& Larew, 1985).

In addition to these assumptions, we suggest the following hypotheses: (a) following Gray, Imp reflects individual differences in the sensitivity to or value of cues for reward (go cues); (b) also following Gray, Anx reflects individual differences in the sensitivity to or value of cues for punishment (no-go cues); (c) the strength of the appetitive associational resources are a positive function of Imp; and (d) the strength of the aversive associational resources are a positive function of Anx.

On the basis of Assumption 5 and Hypotheses $c$ and d, the associational valence of a particular stimulus can be shown to be related to the difference between Imp level and Anx level (see Zinbarg \& Revelle, 1988, for a formal expression and more detailed explication of this model). In other words, the personality traits of Imp and Anx combine to influence the direction of the bias in an individual's associational or interpretive network. Specifically, someone who is more highly anxious than impulsive will be biased in the direction of acquiring negatively valenced associations. Conversely, someone who is more highly impulsive than anxious will be biased in the direction of acquiring positively valenced associations. ${ }^{9}$

According to this model, low anxious, high impulsive individuals are highly sensitive to go cues and are predisposed toward forming appetitive associations. Therefore, according to Assumption 3, low anxious, high impulsive individuals are likely to develop expectations for go cues rapidly. As approach motivation is assumed to be a multiplicative function of go cue expectancies and sensitivity to go cues, it follows that the low anxious, high impulsive individuals would show a relatively fast rate of increase in approach motivation and therefore in response tendencies to go cues.

On the other hand, the high anxious, low impulsive individuals are assumed to be highly sensitive to no-go cues and to be predisposed to forming aversive associations. As a result of their predisposition to form aversive associations, high anxious, low impulsive individuals are likely to develop expectations for nogo cues rapidly. Again, because avoidance motivation is assumed to be a multiplicative function of no-go cue expectancies and sensitivity to no-go cues, the high anxious, low impulsive individuals should experience a relatively fast rate of increase in avoidance motivation and therefore a fast rate of decrease in response tendencies to no-go cues.

Before explaining how the model we have described can account for the Cue Type $\times \operatorname{Imp} \times$ Anx data, we need to consider the possible alternative strategies that would lead to successful discrimination learning in our paradigm. The processing demands required to successfully discriminate the go cues from the no-go cues can be drastically reduced by applying one of two alternative decision rules on the basis of whether the current cue matches expectation. That is, a subject who is successful at learning go cues, and thus is expecting go cues, can use a decision rule in which responses are initiated only if the target matches expectation in order to successfully discriminate go cues from no-go cues. On the other hand, a subject who is successful at learning no-go cues can use a decision rule in which responses are initiated only if the target does not match expectation in order to successfully discriminate go cues from no-go cues.

Following this logic, we explain the effects of Anx in high impulsive individuals in terms of the following two steps: (a) low anxious, high impulsive individuals learn go cues faster and thus form expectations of go cues more rapidly than do the high anxious, high impulsive individuals; and (b) as a result of ex-

\footnotetext{
${ }^{8}$ This is not meant to imply that classically conditioned associations are necessary for expectation formation. We acknowledge that associations, and hence expectations, can result from many sources, including observation and "cognitive" manipulations such as providing an individual with information regarding relevant relations.

${ }^{9}$ We should emphasize that this difference is at the latent-variable level and should not be equated with any difference of scores on such fallible observed scores as those given by the EPI or the STAI. To make strong inferences at the observed score level would require the unrealistic assumption of ratio level of measurement.
} 
pecting cues to be go cues and initiating responses only if a cue matches this expectation, the low anxious, high impulsive individuals also eventually withhold responses to no-go cues even though they have not necessarily learned which cues are nogo cues (in the sense of having formed aversive associations to them).

An examination of the response patterns of the high impulsive subjects provides evidence supporting these two steps. In both Experiments 1 and 3 (Figures 1 and 2), it is clear that the low anxious, high impulsive subjects reached almost asymptotic learning for the go cues by the second block of trials. On the other hand, these subjects did not begin decreasing their response rates to no-go cues until after the second block of trials. This effect is particularly dramatic in Experiment 1 (Figure 1) in which the low anxious, high impulsive subjects actually increased their response rates to no-go cues from Block 1 to Block 2 and then began to decrease their response rates to the no-go cues. This pattern provides support for the notion that the low anxious, high impulsive subjects were successful in learning the go cues and were able to successfully withhold responses to cues that were not go cues only after they were able to identify the go cues.

Similarly, the facilitating effects of high anxiety observed among the low impulsive subjects in Experiments 1 and 3 can be explained in terms of the following two steps: (a) high anxious, low impulsive subjects learn no-go cues faster and thus form greater expectations of no-go cues than do the low anxious, low impulsive subjects; and (b) as a result of expecting cues to be no-go cues and initiating responses only if a cue does not match this expectation, the high anxious, low impulsive subjects also eventually respond to go cues even though they have not necessarily learned which cues are go cues (in the sense of having formed appetitive associations to them).

A close examination of the data for Experiments 1 and 3 reveals some trends that support these two steps. As is particularly evident in Experiment 1 (Figure 1), the high anxious, low impulsive subjects seemed to learn a great deal about no-go cues in the initial block and then did not learn much more about nogo cues during Block 2 , whereas they continued to increase their response rate to go cues. This pattern is consistent with the notion that this group was successful in learning the no-go cues and was able to successfully respond to cues that were not no-go cues once they were able to identify the no-go cues.

It seems, therefore, that a revision of Gray's model, incorporating the concept of expectancies, provides a better fit to these data than does Gray's original model or any of the other three models tested in this investigation. However, the explanation developed in this article for the complex pattern of results involving personality and cue type is speculative and without independent supporting evidence regarding Hypotheses $c$ and $d$. Such evidence would consist of a demonstration that associations, and thus expectations, in go-no-go discrimination paradigms vary as a function of Imp and Anx in the directions suggested by Assumptions 3 and 5 and Hypotheses $c$ and $d$. Furthermore, the data reported in this article cannot be considered a test of the model developed in this section as this model was constructed to fit these data. Clearly, further research is necessary to test the validity of the hypotheses generated in this research.
In making recommendations for further research designed to replicate, extend, and elucidate the processes responsible for the Cue Type $\times \operatorname{Imp} \times$ Anx interaction, it is important to point out that there is at least one additional possible explanation for our results: The observed Cue Type $\times \operatorname{Imp} \times$ Anx interaction may represent a generalized deficit in discrimination learning suggesting differences in intelligence among the personality groups used in our experiments. We do not believe this explanation to be plausible, as theory (Wakefield, 1979) and previous empirical demonstrations (e.g., Hendrickson, 1982; Seddon, 1975) suggest that personality traits such as those we investigated are independent of intelligence. Furthermore, our previous research has shown that if there is any difference in performance, it favors the low anxious subject. This contradicts the explanation that the superior performance of the low impulsive but high anxious subjects was due to greater ability.

\section{Conclusions}

The most important conclusion from this series of experiments is that it is possible to show reliable differences in instrumental behavior as an interactive function of self-reported Imp and Anx. The stable pattern of results found in these four experiments indicates that high anxiety hinders the learning of a gono-go discrimination more among high impulsive individuals than among low impulsive individuals, and it appears that high anxiety may even facilitate discrimination learning among low impulsive individuals.

A second conclusion is that individual differences in instrumental discrimination learning are more closely associated with Imp and Anx than they are with $\mathrm{I} / \mathrm{E}$ and $\mathrm{S} / \mathrm{N}$. Although the results for $I / E$ and $S / N$ are in many ways similar to those for Imp and Anx, the Imp and Anx results were more consistent across all four experiments than were the $\mathrm{I} / \mathrm{E}$ and $\mathrm{S} / \mathrm{N}$ results, and in two of the experiments, the Cue Type $\times \operatorname{Imp} \times$ Anx interaction accounted for a significant increment in the variance explained beyond that explained by $\mathrm{I} / \mathrm{E}$ and $\mathrm{S} / \mathrm{N}$. This conclusion may be considered a conceptual replication and extension of the finding reported by $\mathbf{H}$. J. Eysenck and Levey (1972) that Imp rather than $\mathrm{I} / \mathrm{E}$ is the clearest correlate of classical eyeblink conditioning. This evidence provides further support for the arguments of Gray (1981) that the sources of causal inference lie at the dimensions of Imp and Anx rather than of I/E and S/N (see also H. J. Eysenck, 1987; Gray, 1987; and Revelle, 1987 , regarding this debate).

A third conclusion is that we can order the hypotheses tested in terms of their relative efficacy in explaining the results reported in this article. Eysenck's hypothesis and Gray's hypotheses regarding $\mathrm{I} / \mathrm{E}$ and $\mathrm{S} / \mathrm{N}$ received no support from these results. The failure to find reliable effects of $I / E$ or $S / N$ in this paradigm is not inconsistent with Newman's hypothesis. Spence's and Gray's hypotheses regarding Anx were supported by certain aspects of the Cue Type $\times \operatorname{Imp} \times$ Anx data but were contradicted by other aspects of this data. Therefore, we conclude that Eysenck's hypothesis and Gray's hypotheses regarding $\mathrm{I} / \mathrm{E}$ and $\mathrm{S} / \mathrm{N}$ can be ruled out as explanations for these results. On the other hand, the data do not allow us to unequivocally accept or reject Newman's hypothesis, Spence's hypotheses, or Gray's hypothesis regarding Anx. Further re- 
search pitting these theories against one another is required before we choose among them.

These results must be qualified by again noting that the four theories we tested differ in the range of conditioning phenomenon to which they apply. Thus, although our results suggest that Eysenck's model may be unsuccessful in accounting for individual differences in instrumental conditioning, these results should not necessarily be generalized to the case of classical conditioning in which evidence suggests that Eysenck's model may be successfully applied to classical conditioning (see H. J. Eysenck, 1965, for a review of this literature).

A final conclusion is that a revision of Gray's theory of Imp and Anx incorporating the concept of expectancies can provide a good fit to the results reported in this article. Although Gray's original theory may provide an elegant explanation of behavioral inhibition in rats, it seems that cognitive variables are likely to exert a larger effect on the behavior of humans than on that of rats. In addition to Gray's original hypotheses regarding Imp and Anx, we suggest that there is a relation between these personality traits and the strength of resources devoted to forming affectively valenced associations. As this extension of Gray's theory was generated in order to explain the results we obtained, further research is necessary to test the validity of our hypotheses.

\section{References}

Aronfreed, J. (1968). Conduct and conscience. New York: Academic Press.

Atkinson, J. W. (1957). Motivational determinants of risk-taking behavior. Psychological Review, 64, 359-372.

Barratt, E. (1972). Anxiety and impulsiveness: Toward a neuropsychological model. In C. Spielberger (Ed.), Current trends in theory and research (Vol. I, pp. 195-222). New York: Academic Press.

Barratt, E., \& Patton, J. (1983). Impulsivity: Cognitive, behavioral and psychophysiological correlates. In M. Zuckerman (Ed.), Biological bases of sensation seeking, impulsivity and anxiety (pp. 77-116). Hillsdale, NJ: Erlbaum.

Bird, G. E. (1927). Personality factors in learning. Personnel Journal, 6, 56-59.

Cronbach, L. (1951). Coefficient alpha and the internal structure of tests. Psychometrika, 16, 297-334.

Dollard, J., \& Miller, N. E. (1950). Personality and psychotherapy. New York: McGraw-Hill.

Eysenck, H. J. (1957). The dynamics of anxiety and hysteria. New York: Praeger.

Eysenck, H. J. (1965). Extraversion and the acquisition of eyeblink and GSR conditioned responses. Psychological Bulletin, 63, 258-270.

Eysenck, H. J. (1967). The biological basis of personality. Springfield, IL: Charles C Thomas.

Eysenck, H. J. (1977). Crime and personality. London: Metheun.

Eysenck, H. J. (1987). The place of anxiety and impulsivity in a dimensional framework. Journal of Research in Personality, 21, 489-493.

Eysenck, H. J., \& Eysenck, M. W. (1985). Personality and individual differences: A natural science approach. New York: Plenum Press.

Eysenck, H. J., \& Eysenck, S. B. G. (1975a). Manual of the Eysenck Personality Inventory (2nd ed.). London: Hodder \& Stoughton.

Eysenck, H. J., \& Eysenck, S. B. G. (1975b). Manual of the Eysenck Personality Questionnaire. San Diego, CA: Educational and Industrial Testing Service.

Eysenck, H. J., \& Levey, A. (1972). Conditioning, introversion-extraversion and the strength of the nervous system. In V. Nebylitsyn \& J.
Gray (Eds.), Biological bases of individual behavior (pp. 206-220). New York: Academic Press.

Eysenck, M. W. (1981). Learning, memory and personality. In H. J. Eysenck (Ed.), A model for personality (pp. 169-209). Berlin, West Germany: Springer-Verlag.

Forlano, G., \& Axelrod, H. (1937). The effect of repeated praise or blame on the performance of introverts and extroverts. Journal of Educational Psychology, 28, 92-100.

Gray, J. A. (1981). A critique of Eysenck's theory of personality. In H. J. Eysenck (Ed.), A model for personality (pp. 246-276). Berlin, West Germany: Springer-Verlag.

Gray, J. A. (1982). The neuropsychology of anxiety. Oxford, England: Clarendon Press.

Gray, J. A. (1987). Perspectives on anxiety and impulsivity: A commentary. Journal of research in personality, 21, 493-510.

Gray, J. A., Owen, S., Davis, N., \& Tsaltas, E. (1983). Psychological and physiological relations between anxiety and impulsivity. In $\mathbf{M}$. Zuckerman (Ed.), Biological bases of sensation seeking, impulsivity and anxiety (pp. 189-218). Hillsdale, NJ: Erlbaum.

Grossberg, S. (1987). The adaptive brain I: Cognition, learning, reinforcement, rhythm. Amsterdam: Elsevier.

Hendrickson, D. E. (1982). The biological basis of intelligence part II: Measurement. In H. J. Eysenck (Ed.), A model for intelligence (pp. 197-230). Berlin, West Germany: Springer-Verlag.

Hull, C. L. (1943). Principles of behavior. New' York: Appleton-CenturyCrofts.

Konorski, J. (1948). Conditioned reflexes and neuron organization. New York: Cambridge University Press.

Levey, A., \& Martin, I. (1981). Personality and conditioning. In H. J. Eysenck (Ed.), $A$ model for personality (pp. 123-168). Berlin, West Germany: Springer-Verlag.

Moore, J. W., \& Stickney, K. J. (1985). Antiassociations: Conditioned inhibition in attentional-associative networks. In R. R. Miller \& N. E. Spear (Eds.), Information processing in animals: Conditioned inhibition (pp. 209-222). Hillsdale, NJ: Erlbaum.

Mowrer, O. H. (1969). Psychoneurotic defenses (including deception) as punishment-avoidance strategies. In B. A. Campbell \& R. M. Church (Eds.), Punishment and aversive behavior (pp. 449-466). New York: Appleton-Century-Crofts.

Newman, J. P., Kosson, D. S., \& Howland, E. (1985, May). Response latency following punishment and passive-avoidance learning in extraverts. Paper presented at the meeting of the Midwestern Psychological Association.

Newman, J. P., Widom, C. S., \& Nathan, S. (1985). Passive avoidance in syndromes of disinhibition: Psychopathy and extraversion. Journal of Personality and Social Psychology, 48, 1316-1327.

Patterson, C. M., Kosson, D. S., \& Newman, J. P. (1987). Reaction to punishment, reflectivity, and passive avoidance learning in extraverts. Journal of Personality and Social Psychology, 52, 565-575.

Pavlov, I. (1927). Conditioned reflexes. (G. V. Anrep, Ed. and Trans.). London: Oxford University Press.

Revelle, W. (1979). Hierarchical cluster analysis and the internal structure of tests. Multivariate Behavioral Research, 14, 57-74.

Revelle, W. (1987). Personality and motivation: Sources of inefficiency in cognitive performance. Journal of Research in Personality, 21, 436-453.

Revelle, W., Humphreys, M., Simon, L., \& Gilliland, K. (1980). The interactive effect of personality, time of day and caffeine: $A$ test of the arousal model. Journal of Experimental Psychology: General, 109, 131.

Rocklin, T., \& Revelle, W. (1981). The measurement of extraversion: A comparison of the Eysenck Personality Inventory and the Eysenck Personality Questionnaire. British Journal of Social Psychology, 20, 279-284. 
Rotter, J. B. (1964). Clinical psychology (2nd ed.). Englewood Cliffs, NJ: Prentice-Hall.

Schmajuk, N. A., \& Moore, J. W. (1986). A real-time attentional-associative network for classical conditioning of the rabbit's NMR. In Proceedings of the Eighth Annual Conference of the Cognitive Science Society (pp. 794-807). Hillsdale, NJ; Erlbaum.

Seddon, G. M. (1975). The effects of chronological age on the relationship of intelligence and academic achievement with extraversion and neuroticism. British Journal of Psychology, 66, 493-500.

Spence, J. T., \& Spence, K. W. (1966). The motivational components of manifest anxiety: Drive and drive stimuli. In C. D. Spielberger (Ed.), Anxiety and behavior (pp. 291-326). New York: Academic Press.

Spence, K. W. (1964). Anxiety (drive) level and performance in eyelid conditioning. Psychological Bulletin, 61, 137-142.

Spence, K. W., \& Taylor, J. A. (1951). Anxiety and strength of UCS as determinants of amount of eyelid conditioning. Journal of Experimental Psychology, 42, 183-188.

Spielberger, C. D., Gorsuch, R., \& Lushene, R. (1970). The State-Trait Anxiety Inventory (STAI) Test Manual Form X. Palo Alto, CA: Consulting Psychologists Press.

Thompson, G. C., \& Hunnicutt, C. W. (1944). The effect of repeated praise or blame on the work achievement of "introverts" and "extroverts". Journal of Educational Psychology, 35, 257-266.
Trasler, G. (1978). Relations between psychopathy and persistent criminality-methodological and theoretical issues. In R. D. Hare \& D. Schalling (Eds.), Psychopathic behaviour: Approaches to research (pp. 273-298). New York: Wiley.

Wagner, A. R., \& Larew, M. B. (1985). Opponent processes and Pavlovian inhibition. In R. R. Miller \& N. E. Spear (Eds.), Information processing in animals: Conditioned inhibition (pp. 223-266). Hillsdale, NJ: Eribaum.

Wakefield, J. A. (1979). Using personality to individualize instruction. San Diego, CA: Educational and Industrial Testing Service.

Weiner, B. (1966). The role of success and failure in the learning of easy and complex tasks. Journal of Personality and Social Psychology, 3, 339-344.

Weiner, B., \& Schneider, K. (1971). Drive versus cognitive theory: A reply to Boor and Harmon. Journal of Personality and Social Psychology, 18, 258-262.

Zinbarg, R., \& Revelle, W. (1988). Individual differences in the processing of affective stimuli: Mutual inhibition in an adaptive system. Unpublished manuscript.

Received March 1, 1988

Revision received December 31, 1988

Accepted January 12, 1989

\section{APA Convention "Call for Programs"}

The "Call for Programs" for the 1990 APA annual convention will be included in the October issue of APA Monitor. The 1990 convention will be held in Boston, Massachusetts, from August 10 through August 14. Deadline for submission of program and presentation proposals is December 15,1989 . This earlier deadline is required because many university and college campuses will close for the holidays in mid-December and because the convention is in mid-August. Additional copies of the "Call" will be available from the APA Convention Office in October. 